\title{
Evolution of subglacial water pressure along a glacier's length
}

\author{
Joel T. HARPER, ${ }^{1}$ Neil F. HUMPHREY, ${ }^{2}$ W. Tad PFEFFER, ${ }^{3}$ Tyler FUDGE, ${ }^{2}$ Shad $\mathrm{O}^{\prime} \mathrm{NEEL}^{3}$ \\ ${ }^{1}$ Department of Geology, University of Montana, Missoula, MT 59812, USA \\ E-mail: joel@mso.umt.edu \\ ${ }^{2}$ Department of Geology and Geophysics, PO Box 3006, University of Wyoming, Laramie, WY 82071-3006, USA \\ ${ }^{3}$ Institute of Arctic and Alpine Research, University of Colorado, Boulder, CO 80309-0450, USA
}

\begin{abstract}
Observations from along the length of Bench Glacier, Alaska, USA, show that the subglacial water-pressure field undergoes a multiphase transition from a winter mode to a summer mode. Data were collected at the glacier surface, the outlet stream, and in a network of 47 boreholes spanning the length of the $7 \mathrm{~km}$ long glacier. The winter pressure field was near overburden, with low-magnitude (centimeter to meter scale) and long-period (days to weeks) variations. During a spring speed-up event, boreholes showed synchronous variations and a slight pressure drop from prior winter values. Diurnal pressure variations followed the speed-up, with their onset associated with a glacier-wide pressure drop and flood at the terminus stream. Diurnal variations with swings of up to $80 \%$ of overburden pressure were typical of mid-summer. Several characteristics of our observations contradict common conceptions about the seasonal development of the subglacial drainage system and the linkages between subglacial hydrology and basal sliding: (1) increased water pressure did not accompany high sliding rates; (2) the drainage system showed activity characteristic of the spring season long before abundant water was available on the glacier surface; (3) the onset of both spring activity and diurnal variations of the drainage system did not show a spatial progression along the length of the glacier.
\end{abstract}

\section{INTRODUCTION}

As the present climate warms, meltwater hydrology and water's influence on glacier motion will be an increasingly important aspect of thermal and dynamic processes of Greenland and other large ice masses. Basal decoupling, caused by water routed from the surface to the bed, has been invoked as an explanation for the recent rapid motion and thinning of outlet glaciers in Greenland (Krabill and others, 1999; Thomas and others, 2000). New observations offer strong support to this postulate, including Zwally and others' (2002) discovery of a correlation between meltwater generation and motion of the ice sheet, and Abdalati and others' (2003) report that Jakobshavn Isbræ, Greenland, has recently demonstrated greater motion in summer than in spring. With influence on sea level, ocean circulation and the general climate system, the sliding stability of Greenland and other ice sheets has strong bearing on globally important processes and thus warrants full understanding. Unfortunately, in situ investigations of the mechanical linkages between water input and enhanced motion are difficult, if not impossible, on the vast and thick ice sheets. This problem motivates interest in the hydrology and dynamics of smaller mountain glaciers, where the manageable scale can be utilized to investigate key glaciological processes with the goal of up-scaling.

Glaciers commonly experience enhanced sliding during the spring melt season (see Willis, 1995 for a review) implying that meltwater input, or a significant change therein, ultimately leads to increased sliding. Water input will become significant only after the snowpack is saturated and surface melt can be routed into the glacier (Fountain, 1996). Meltwater input often increases throughout the summer, but enhanced sliding events commonly occur in spring. This implies that the initial rapid increase in water is more important to sliding than the actual quantity of water input (Röthlisberger and Lang, 1987; Fountain and Walder,
1998). Physical models of basal coupling suggest a rising influx of water produces a pressure increase which then promotes sliding (e.g. Röthlisberger, 1972; Fowler, 1987). A common speculation is that in spring time, pressure increases result from new input to a system incapable of efficiently draining water from the bed. As water flux at the bed increases, orifices enlarge to conduits (Kamb, 1987) and a more efficient drainage system eventually develops, which lowers the pressure. Since water flux at the bed is driven by surface meltwater generation, the establishment of a conduit drainage system is expected to follow the melt pattern, progressing upward along a glacier's length (Fountain and Walder, 1998). Nienow and others (1998) have in fact inferred from dye-tracer experiments that at Haut Glacier $d^{\prime}$ Arolla, Switzerland, the formation of fast conduit drainage at the bed closely tracks the transient snowline at the glacier surface.

Here we present observations of late-winter and spring development of the subglacial drainage system. Our data include measurements made in boreholes drilled to the bed and fitted with sensors, surface velocity measurements, and information about surface melt conditions. Our dataset is unique in its spatial and temporal character: our borehole locations span the length of the glacier and our data were collected for a period in excess of 16 months. In this paper, we focus on select characteristics of the along-glacier evolution of subglacial water pressure. Further analysis, such as comparison between pressure/storage and high time/ space resolution measurements of bed separation and ice motion (i.e. work that builds upon ideas set forth by Iken (1981) and Iken and others (1983)) will be treated elsewhere. The data presented here will focus on the winter and spring of 2003, but we will make reference to observations made during the same periods of 2002. Along-glacier observations come from sensors installed in spring 2002, and detailed local observations are derived from a grid of boreholes installed early spring 2003. Our data suggest that 


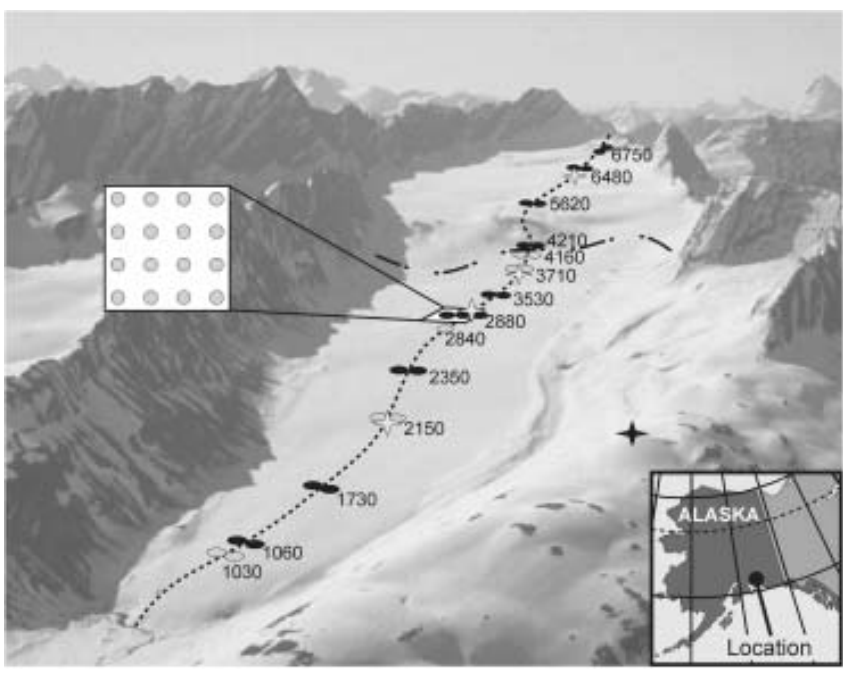

Fig. 1. Southward-looking view of Bench Glacier. Ovals show locations of boreholes drilled in 2002 (black fill) and 2003 (gray fill). Spacing between boreholes in the 2003 grid (inset) is $20 \times 20 \mathrm{~m}$. Four GPS roving stations located on glacier (stars) and the GPS-base and meteorological station (filled star) are shown. Approximate center line of glacier is shown by short-dashed line, which is roughly $7 \mathrm{~km}$ long. Long-dashed line shows approximate position of the equilibrium line.

(1) the timing of initial subglacial activity is earlier in spring than expected; (2) there is no major pressure increase associated with an otherwise typical spring speed-up; (3) there is no up-glacier (or down-glacier) progression of evolutionary changes to the subglacial drainage system.

\section{FIELD SITE AND DATA COLLECTION}

Experiments were conducted at Bench Glacier, Alaska, USA, a temperate valley glacier located in the Chugach Mountains (Fig. 1). The glacier is approximately $7 \mathrm{~km}$ in length, spans approximately $1200 \mathrm{~m}$ in elevation and has a simple geometry with no tributaries. The glacier surface averages about $10^{\circ}$, with one steeper $20-30^{\circ}$ crevassed ramp located just above the equilibrium-line altitude (ELA). With a median elevation of roughly $1400 \mathrm{~m}$, but located $<50 \mathrm{~km}$ from the Pacific Ocean, Bench Glacier has high mass flux typical of coastal Alaska: winter accumulation is on the order of 1-1.5 m w.e. Like many other glaciers in the region, Bench Glacier has been thinning and retreating during recent decades.

\subsection{Boreholes and the bed}

Radar imaging of the bed shows that the glacier has a parabolic cross-section and the bed slopes smoothly along the glacier's length with no major overdeepenings. Ice thickness is $150-210 \mathrm{~m}$ over most of the distance between the ELA and the terminus. The glacier is underlain by steeply dipping metamorphosed sedimentary rock. We characterize the bed as 'hard', based on observations from $>50$ boreholes spaced along the glacier. The observations include penetrometer tests, borehole video imaging, and close monitoring of the drill tip as it encountered the bed. While it is possible, and perhaps likely, that till is present in patches that are locally thick (i.e. meters) or widespread and thin (i.e. decimeters), evidence is lacking for large areas where till is meters thick.
Boreholes were drilled by hot-water methods during spring (May to early June) 2002 and 2003. Preliminary knowledge of the bed's location was obtained by highfrequency radar imaging. When the drill failed to advance near the bed, it was reversed and readvanced repeatedly for 20-30 min in an effort to penetrate englacial and/or subglacial debris (if any). Rarely did the drill advance from the initial point of stoppage, and never for more than a few decimeters. We interpret this to mean that the borehole connected to the bed. The boreholes, however, did not drain upon connection, which we attribute to the hydrologic conditions of early spring as discussed later.

Drill sites spanned the length of the $7 \mathrm{~km}$ long glacier (Fig. 1). In 2002, 19 holes were drilled and fitted with sensors for measuring water pressure, conductivity, turbidity and flow velocity. In 2003, 25 additional holes were instrumented at five sites, one of which included 16 holes in a $4 \times 4$ grid with $20 \mathrm{~m}$ orthogonal spacing. The 2003 holes were fitted with sensors for measuring water pressure and flow velocity. All sensors were located at the base of the borehole and were monitored with dataloggers on the glacier surface. The dataloggers had sufficient power and storage to collect measurements every few minutes for up to 2 years. We note that later in this paper we refer to our measurements of borehole water level as measurements of subglacial water pressure. We thus consider the borehole to act as a manometer, the assumptions of which are discussed by Harper and others (2002).

\subsection{Glacier motion}

Surface velocities were measured at four locations (Fig. 1) with survey grade global positioning system (GPS) units fixed to the glacier surface. GPS solutions were differentially corrected using base station solutions from a unit located on bedrock at the glacier margin. Data were collected at $5 \mathrm{~min}$ intervals and averaged to 1 hour positions. To generate a velocity series, the positional time series was differentiated and filtered using Savitzky-Golay methods (Orfanidis, 1995) which attempts to preserve high-frequency variations (thus assuming the glacier is capable of sudden motion events).

\subsection{Surface melt and stream discharge}

In late fall 2002, the datalogger enclosures were positioned on the snow/ice interface at the nine borehole sites along the glacier. Temperature records from within the enclosures can be used to infer two key factors related to the timing and spatial progression of meltwater input during spring 2003:

1. The day when the snowpack became isothermal $\left(0^{\circ} \mathrm{C}\right)$ and thus meltwater could move freely within the snowpack to enter the glacier. There may have been a slight delay between warming of the snow and warming of the enclosure, but the enclosure had little thermal mass and so we expect the delay was no more than 1 day.

2. The upward progression of the transient snowline and exposure of bare ice. This is identified by the initiation of diurnal swings in temperature, which appear almost instantly in the records. The enclosure is $5 \mathrm{~cm}$ high, and may have become exposed to sun before the last few $\mathrm{cm}$ of snow were ablated from the ice surface. Our estimates therefore represent a minimum date for the exposure of ice. 


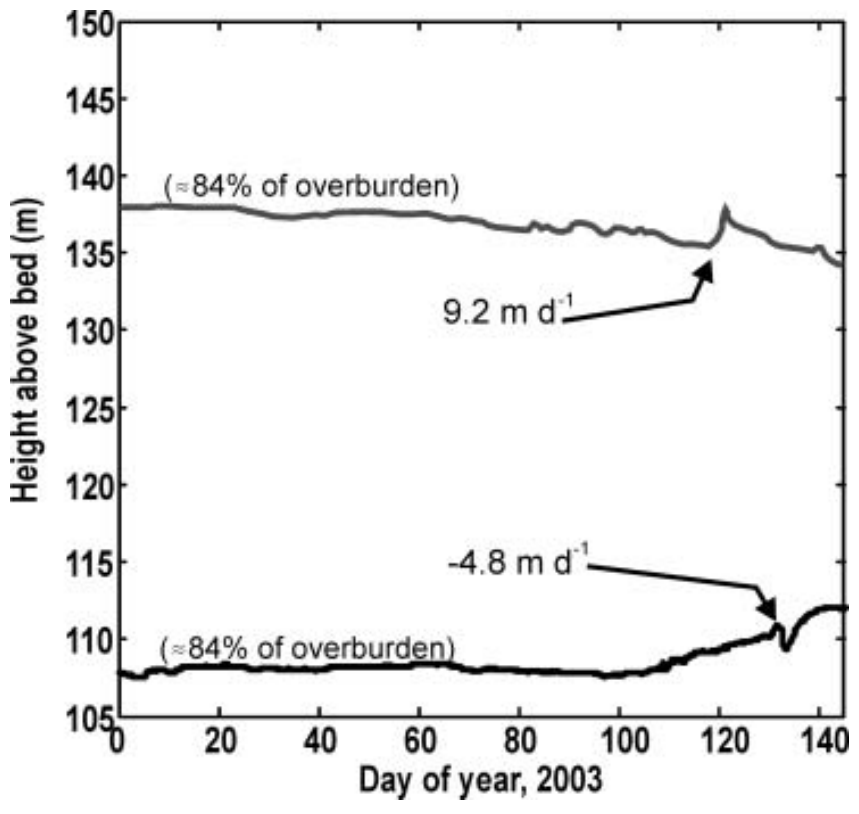

Fig. 2. Examples of winter and spring 'wake-up' pressure records (data plotted as water level to avoid overlap) from two separate boreholes (black and gray lines). Winter pressures were high and showed little variability; the spring wake-up event is defined as the first major change in water level of at least several $\mathrm{md}^{-1}$ in magnitude.

Stream stage was measured by a pressure transducer in the outlet stream. The stage data are not converted to discharge because we lack a stable stage rating curve for the outlet stream. Stage data do provide information about diurnal variations and relative discharge events.

\section{RESULTS: PHASES OF DRAINAGE DEVELOPMENT}

\section{1. 'Wake-up' phase}

The borehole sensors installed in 2002 provide a record of winter and early-spring activity in 2003. During winter, water pressures were generally high, typically at least $80 \%$ of overburden (Fig. 2). A few holes showed slow and steady decreases in pressure during the winter, but most holes attained a fixed pressure by late fall (see Fudge and others, 2005) and maintained this pressure until spring. A common characteristic of winter pressures was that variations were small and slow (i.e. centimeter to meter changes over weeks), in contrast to spring and summer when variations were typically both rapid and large (i.e. meter to tens of meter changes in hours to days).

Based on these characteristic behaviors, a spring 'wakeup' event stands out in all of the overwinter records. This is the first occurrence of a sudden large change in water level (Fig. 2). Each borehole's record is unique, making it difficult to assign a common quantitative threshold for this event; the event, however, was always on the order of a 3-10 m change in water level occurring over 1 day or less. After the wakeup, the boreholes showed minor variations (meter scale) that lasted hours to days and were asynchronous between holes. All of the 2002 holes were frozen over at or near the surface due to high stands in the zone affected by the winter cold wave. Consequently, we believe this wake-up activity represents an actual bed event as opposed to surface water flowing down boreholes.
Table 1. Day of 2003 of events at borehole sites along the glacier

2002 site Isothermal snow Pressure 'wake-up' Bare ice exposed

$\begin{array}{lccc}1060 & 119 & 117 & \text { no data } \\ 1730^{*} & 117 & 118,123 & 189 \\ 2350^{*} & 118 & 122,143 & 194 \\ 2880 & 118 & 120 & 199 \\ 4210^{*} & 145 & 128,130 & 211\end{array}$

*Observations available from two different boreholes at site.

The wake-up occurred at sites below the ELA within a few days of the local snowpack reaching isothermal conditions (Table 1). The snowpack became isothermal across the lower two-thirds of the ablation zone over a period of a few days, but the upward progression of isothermal conditions slowed considerably along the upper $2 \mathrm{~km}$ of the ablation zone. The ELA site became isothermal 3 weeks after the lower glacier. Basal activity at the ELA site, however, was only about 1 week delayed from lower on the glacier. Hence, the wakeup at the ELA site occurred 2 weeks before meltwater was abundant in snow in this area.

\section{2. 'Event' phase}

A roughly 2 week period (days 150-165) formed the transition between early wake-up activity and mid-season diurnal variations of water pressure. During this period, which we term the 'event phase', both the velocity and pressure records demonstrated a high level of activity that was unique to this time of year. The surface velocity field underwent a two-stage speed-up, where it reached levels six times greater than early/late-season values of $0.03-$ $0.04 \mathrm{~m} \mathrm{~d}^{-1}$. We assume that the increased surface velocity represents enhanced sliding as is typical of spring speed-up events observed on many glaciers (e.g. Willis, 1995). The velocity at site $2880 \mathrm{~m}$, located in the middle of the grid of 16 boreholes, first peaked at $0.17 \mathrm{~m} \mathrm{~d}^{-1}$ on day 158.6 (Fig. 3a). It then slowed for about 1.5 days, and then underwent a second speed-up to $0.25 \mathrm{~m} \mathrm{~d}^{-1}$ about 2.5 days later. Due to an instrumentation malfunction, the record temporarily ended on day 164 . However, by back-projecting the position of the GPS receiver after measurements resumed, day 164 appears to be no more than 1 day before the glacier began to slow down (Fig. 3b).

We first examine the relationship between pressure and the speed-up at the decameter scale using data from the 16-hole grid that covers an area of $3600 \mathrm{~m}^{2}$ (Fig. 4a). Within the event phase, the pressure records show two different stages that correspond to details of the velocity record. The first extends from day 151 to 157 and covers the period preceding velocity increases. This stage initiates with a sudden $20 \mathrm{~m}$ drop of water levels experienced by $75 \%$ of the holes. Over the following 5 days, the holes showed irregular variations at time-scales of hours to days. Pressures steadily rose but not to their levels of before the day 151 drop. Importantly, this characterization describes $75 \%$ of the holes; the other $25 \%$ showed irregular and differing behavior.

The second stage of the event phase begins at day 157 and lasts until day 165. This stage corresponds to the velocity speed-up events and is a period when every borehole showed nearly identical pressure variations. During the transition between stages there are large 


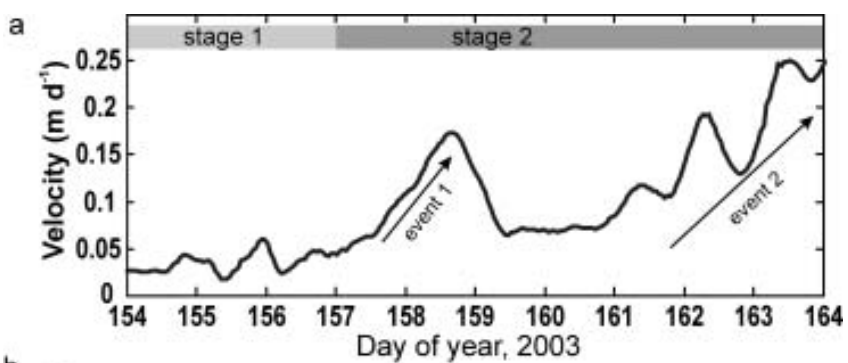

b

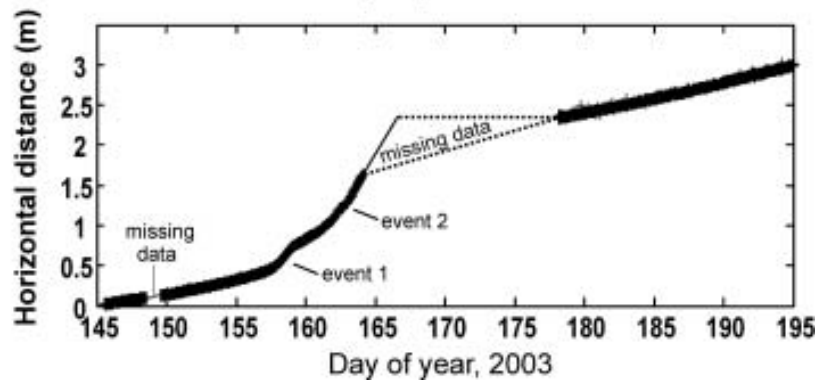

Fig. 3. Surface motion measured by GPS at site 2880, the location of the 16-borehole grid. (a) Velocity series with two speed-up events. Stages 1 and 2 correspond to pre- and post-speed-up activity and correlate with pressure records shown in Figure 4. (b) Position series with speed-up events and data gap between days 164 and 178. Projecting the series forward from the start of the data gap (solid line) gives a time range for the end of event 2 high velocity (dotted lines), assuming no backwards motion. This analysis suggests the velocity began to slow down between days 164 and 166 .

(e.g. $5 \mathrm{~m} \mathrm{~h}^{-1}$ ) pressure spikes, while during the entire second speed-up event there are no such pressure spikes. Importantly, the speed-up is the only time of year when adjacent boreholes show virtually identical variations in water pressure (cf. Fig. 4b).

The pattern of minor pressure variations differed at sites along the glacier. Yet, all borehole records were similar in that they show no major pressure increase associated with the high velocities; rather, a small drop from winter values as the speed-up passed was typical. Additionally, a two stage speed-up at Bench Glacier in spring 2002 is reported by other workers (Anderson and others, 2004) and our borehole data show no pressure increase associated with that speedup either.

\subsection{Establishment of diurnal variations}

The event phase terminated with a 5 day period of decreasing water levels at sites along the length of the ablation zone and all 16 holes of the grid (Fig. 5a). There was no detectable up-glacier progression of the draining, but instead it appeared to be simultaneous at all locations. The lowering of water levels was concurrent with a period which we interpret to be flooding at the outlet stream (Fig. 5b). Following the pressure drop and flooding, large diurnal pressure swings then initiated at many locations and remained active until late summer (Fig. 4b). Widespread draining preceded the first appearance of diurnal variations in both 2002 and 2003, but the drainage of a borehole was not a prerequisite: many holes in both years initiated diurnal variations without undergoing a major drainage event.

During both 2002 and 2003 the initiation of diurnal swings neither progressed along the glacier nor was it simultaneous at all locations (Table 2). Instead, the diurnal
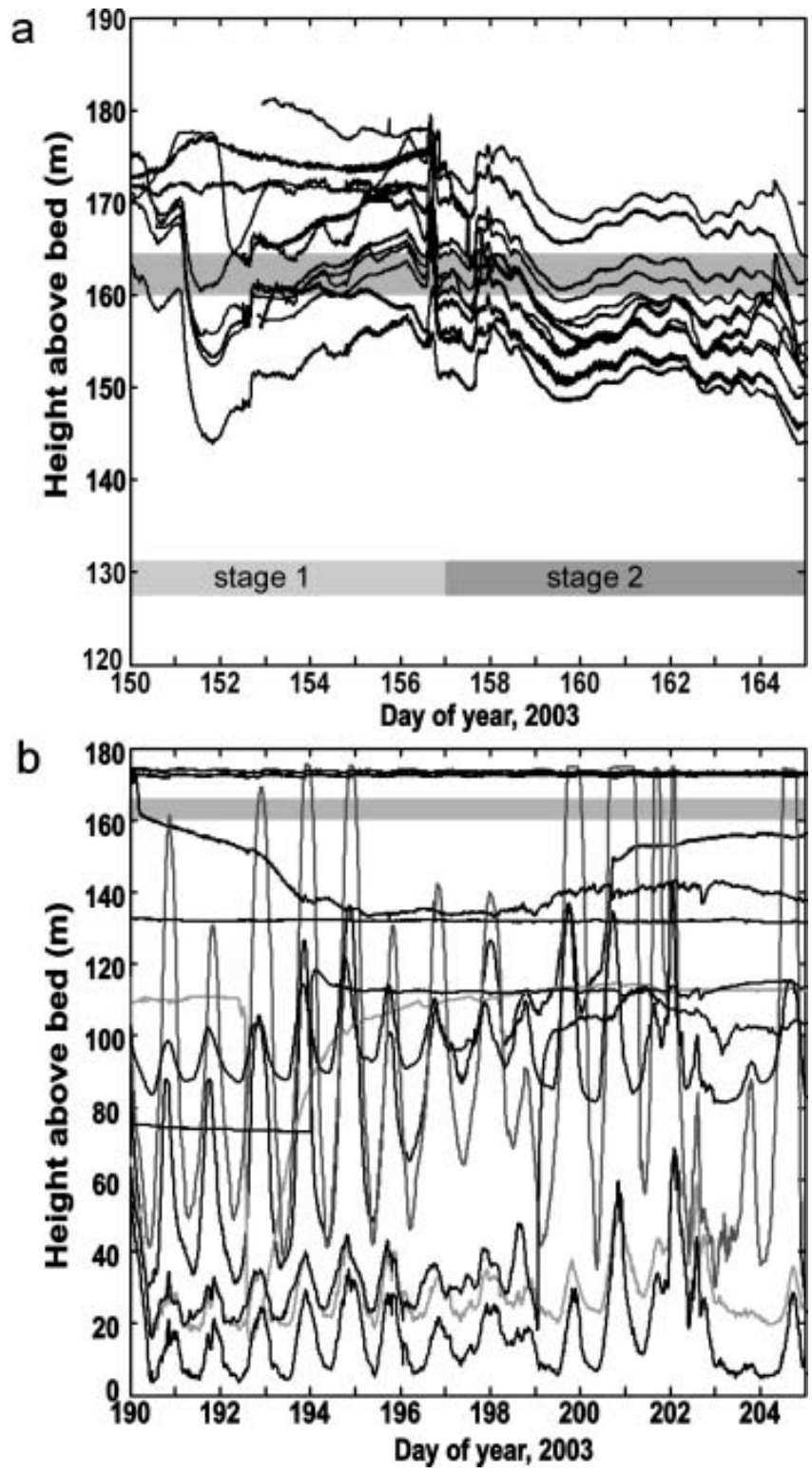

Fig. 4. Borehole water levels from the grid of 16 boreholes spaced $20 \times 20 \mathrm{~m}$ at site 2880 . Gray bars through data show region where water levels equal overburden pressure (data plotted as water level to avoid overlap). (a) Record during the spring event phase. Stage 1 is before the speed-up; stage 2 corresponds to rapid sliding event and is the only time of the year when all boreholes show a high degree of synchroneity. (b) Record from mid-summer, when diurnal variations are common but there is a high degree of spatial variability and large pressure gradients between holes.

swings began close in time at several points along the glacier's length, and then remaining sites followed at various delays of up to 40 days. In 2002, sites near the ELA showed strong diurnal swings early in the year; in 2003 no diurnal swings were recorded in boreholes within $1.5 \mathrm{~km}$ of the ELA. Spatial gradients in pressure of up to $78 \mathrm{kPam}^{-1}$ were common during the period of diurnal activity (Fig. 4b). In some cases, only one of two adjacent holes underwent diurnal swings; in other cases, both holes showed swings but with a significant pressure gradient between the two. Some adjacent holes did, however, have identical pressure records. Diurnal variations were present at some locations through the late fall; the timing and pattern of their termination is discussed by Fudge and others (2005). 

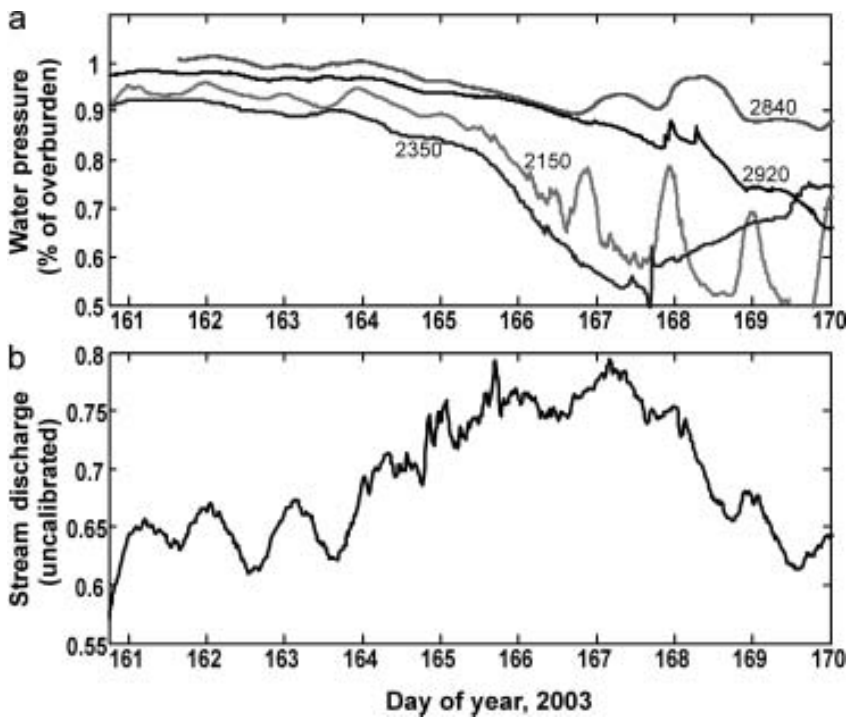

Fig. 5. Borehole draining and terminus-stream flooding event. (a) Water levels in four holes along the glacier show declining water level between about days 164 and 168. (b) Record from stage measurement at terminus stream. High discharge and dampened diurnal variations occur between about days 164 and 168 .

\subsection{Accumulation area}

Data from instruments located in the accumulation zone are, unfortunately, not available for the 2003 spring period. Measurements from 2002, however, show that pressure in the accumulation zone made irregular variations, but had no strong diurnal character. One major draining event occurred, and at times pressure approached atmospheric in one of the six accumulation area boreholes. These boreholes were installed after the wake-up event had occurred elsewhere on the glacier, so it is unclear if this area experiences such events.

\section{DISCUSSION AND CONCLUSIONS}

Our observations from Bench Glacier have several characteristics that counter common conceptions about the development of the subglacial drainage system and the link between hydrology and basal sliding.

1. Surface melt and the bed. The basal water-pressure field demonstrated spring activity long before abundant water was available on the glacier surface, before significant surface melt had occurred and only days after the surface snowpack became isothermal. The highest site in the ablation zone even showed activity 2 weeks prior to a wet snowpack. There are several possible interpretations of this result. One is that surface-to-bed pathways are in place in early spring, perhaps year-round, and have little capacity for water storage. Meltwater input would thus influence the bed with little time delay. A second interpretation is that the initial spring activity of the basal hydrology system was caused by water input from melting snow on the valley walls. We observed that due to a high angle of incidence to the sun, snow on the east valley wall melted earlier and faster than on the glacier surface. This explanation would require that meltwater is capable of fast routing from the margins to the glacier center line. Also, the steep valley walls hold a shallow
Table 2. Start day of large diurnal pressure swings

\begin{tabular}{ccc}
\hline Year & Site & Day \\
\hline 2002 & $1730^{*}$ & 194,196 \\
2002 & $2350^{*}$ & 175,213 \\
2002 & 2890 & 180 \\
2002 & $4210^{*}$ & 180,182 \\
& & \\
2003 & $1030^{*}$ & 201,202 \\
2003 & $1730^{*}$ & 213,213 \\
2003 & $2150^{*}$ & 167,167 \\
2003 & $2880^{+}$ & 169 \\
\hline
\end{tabular}

*Two holes at site, spaced $20 \mathrm{~m}$ apart.

+16-hole grid with $20 \times 20 \mathrm{~m}$ spacing.

winter snowpack and thus do not provide a significant quantity of meltwater. No matter which scenario or scenarios is true, all suggest that there was only a small volume of water at the bed since a small influx produced an appreciable response.

2. Water pressure and sliding. No pressure increase accompanied high sliding velocity during the spring speed-up. In fact, the pressure was at least as high during most of the winter as it was during the high-speed event. This result contradicts the common notion that high pressure from water input to a poorly developed drainage system is the cause of spring speed-up events. The marked synchroneity of pressure records in 16 holes (Fig. 4a, stage 2) is unique to this period of the speed-up event. The similarity of records suggests that a large fraction of the bed was covered by water (all 16 holes were well connected) and that locations holding water were interconnected. We conjecture that the partial synchroneity and high-frequency events of stage 1 represent basal flooding and cavity connections forming during local reorganizations. Stage 2 was rapid sliding on well-connected cavities covering much of the bed. The minor pressure fluctuations experienced by every hole during this period could have been caused by ice overburden variations related to the dynamics of rapid sliding.

3. Along-glacier development of drainage. Both the initiation of basal activity in early spring, and the establishment of diurnal pressure swings did not show a steady up-glacier progression. This is also an unexpected result, as it counters both conceptual reasoning that it should progress upward from the terminus (Fountain and Walder, 1998) and observations that suggest conduit drainage is established following the upward progression of the transient snowline (Nienow and others, 1998). At Bench Glacier, large diurnal pressure swings (suggesting conduit drainage) were fully established 2-4 weeks before bare ice was exposed on the glacier surface. Further, the observed pattern to the start of diurnals, where a few points up and down the glacier began close in time and then scattered locations followed, does not suggest a headward growth of a drainage system. A similar pattern occurred with the end-of-season shutdown of the drainage system (Fudge and others, 2005). Consequently, it is possible to have two points meters apart that have vastly different drainage systems, but 
points kilometers apart along the glacier that are connected by a linked drainage system.

Had our measurements been limited to one or two sites along the glacier, or restricted to any given month, our view of the hydrology of Bench Glacier would be far different than the above observations yield. Hence, we conclude that to understand the linkages between subglacial hydrology and sliding, we must approach the problem at the full glacier scale.

\section{ACKNOWLEDGEMENTS}

We thank the University Navstar Consortium for GPS equipment; VECO Polar Resources and D. and L. Bradley for logistical support; J. Johnson for his work as scientific editor; and J.L. Fastook and L. Stearns for their reviews of the manuscript. This work was funded by the US National Science Foundation Office of Polar Programs, Arctic Natural Sciences (OPP-0118488).

\section{REFERENCES}

Abdalati, W., S. Manizade, J. Golder, R.H. Thomas, W. Krabill and B. Csatho. 2003. Recent increase in flow rates of the Jakobshavn Isbræ, Greenland. [Abstract C21D-06. F370.] Eos, 84(46), Fall Meeting Suppl.

Anderson, R.S. and 6 others. 2004. Strong feedbacks between hydrology and sliding of a small alpine glacier. J. Geophys. Res., 109(F3), F03005. (10.1029/2004JF000120.)

Fountain, A.G. 1996. Effect of snow and firn hydrology on the physical and chemical characteristics of glacier runoff. Hydrol. Proc., 10, 509-521.

Fountain, A.G. and J.S. Walder. 1998. Water flow through temperate glaciers. Rev. Geophys., 36(3), 299-328.

Fowler, A.C. 1987. Sliding with cavity formation. J. Glaciol., 33(115), 255-267.
Fudge, T.J., J.T. Harper, N.F. Humphrey and W.T. Pfeffer. 2005. Diurnal water-pressure fluctuations: timing and pattern of termination below Bench Glacier, Alaska, USA. Ann. Glaciol., 40 (see paper in this volume).

Harper, J.T., N.F. Humphrey and M.C. Greenwood. 2002. Basal conditions and glacier motion during the winter/spring transition, Worthington Glacier, Alaska, U.S.A. J. Glaciol., 48(160), $42-50$.

Iken, A. 1981. The effect of the subglacial water pressure on the sliding velocity of a glacier in an idealized numerical model. J. Glaciol., 27(97), 407-421.

Iken, A., H. Röthlisberger, A. Flotron and W. Haeberli. 1983. The uplift of Unteraargletscher at the beginning of the melt season a consequence of water storage at the bed? J. Glaciol., 29 (101), $28-47$.

Kamb, B. 1987. Glacier surge mechanism based on linked cavity configuration of the basal water conduit system. J. Geophys. Res., 92(B9), 9083-9100.

Krabill, W. and 8 others. 1999. Rapid thinning of parts of the southern Greenland ice sheet. Science, 283(5407), 1522-1524.

Nienow, P., M. Sharp and I. Willis. 1998. Seasonal changes in the morphology of the subglacial drainage system, Haut Glacier d'Arolla, Switzerland. Earth Surf. Process. Landforms, 23(9), 825-843.

Orfanidis, S.J. 1995. Introduction to signal processing. Upper Saddle River, NJ, Prentice Hall.

Röthlisberger, H. 1972. Water pressure in intra- and subglacial channels. J. Glaciol., 11(62), 177-203.

Röthlisberger, H. and H. Lang. 1987. Glacial hydrology. In Gurnell, A.M. and M.J. Clark, eds. Glacio-fluvial sediment transfer: an alpine perspective. Chichester, etc., Wiley, 207-284.

Thomas, R.H. and 8 others. 2000. Substantial thinning of a major east Greenland outlet glacier. Geophys. Res. Lett., 27(9), 1291-1294.

Willis, I.C. 1995. Intra-annual variations in glacier motion: a review. Prog. Phys. Geogr., 19(1), 61-106.

Zwally, H.J., W. Abdalati, T. Herring, K. Larson, J. Saba and K. Steffen. 2002. Surface melt-induced acceleration of Greenland ice-sheet flow. Science, 297(5579), 218-222. 